\title{
Measures to Increase Recoveries and Avoid Concentrate Disposal: Principles to Control Scaling and Reduce Concentrate Disposal in Reverse Osmosis Applications
}

\author{
Alexei Pervov*
}

Moscow State University of Civil Engineering, Russian Federation

\begin{abstract}
The present work is aimed at development of a new approach to reduce RO concentrate flow and to increase recovery. The described techniques enable us to remove calcium carbonate from RO concentrate by means of "seed" crystallization. These proposed techniques use "open channel" spiral wound membrane modules that can directly treat water with high scaling and fouling potentials without pretreatment. The experimental procedure is described and experimental plots are presented that describe precipitation kinetics. The test membrane unit was operated in circulation mode and recovery values reach $95 \%$ or higher. RO concentrate constantly passed through the precipitation reactor where seed crystals were contained. Seed crystal formation was initiated by injecting caustic solution to RO concentrate. The driving force for crystal growth was constantly created by RO process due to increase of calcium and carbonate ion concentration values.

Fouling control is achieved by providing sufficient cross flow velocities, flushings and cleanings. Coagulated suspended matter after membrane flushes is collected, sedimented and finally dewatered. The concentrated solution that contains rejected salts and impurities constitutes no more than 1 per cent of initial feed water volume and can be withdrawn together with wet sludge as a sludge moisture. The described technical procedure enables us to completely utilize concentrate and produce quality product water, softened water and sludge.
\end{abstract}

Keywords: Reverse osmosis concentrate, concentrate utilization, calcium carbonate precipitation, seed crystallization.

\section{INTRODUCTION}

Pretreatment and concentrate disposal - two main factors that limit Reverse Osmosis applications in water treatment.

Conventional (classical) water treatment techniques used to remove color, TOC and pathogenic microorganisms from natural surface water, were developed in the 1970-s. They were based on principles of coagulation, sedimentation, clarification, filtration, chlorination. Today, the deteriorating state of natural water quality (increase of TOC, halogenocarbons, pesticides, surfactants etc.) requires development and application of more efficient techniques. Also, conventional clarification processes used for municipal drinking water production create serious ecological problems as they discharge water that contains flocculation chemicals after sludge dewatering.

Modern techniques of quality drinking water production, which combine clarification, oxidation, sorption and membrane ultrafiltration techniques [1] are recognized as "breakthrough". This approach was successfully implemented by Degremont Co. at several

*Address correspondence to this author at the Moscow State University of Civil Engineering, Russian Federation; E-mail: ale-pervov@yandex.ru water facilities that supply drinking water to Paris, France [2]. Here, ultrafilltration membranes act as a "barrier" to activated carbon particles, bacteria and viruses. Oxidation and sorption techniques, despite efficiently removing organics, are expensive to run because of the cost of sorption material. Nanofiltration membranes also effiently reject organic compounds and halogenocarbons. Though nanofiltration provides an efficient reagent-free solution to remove a number of impurities, there are some serious reasons that keep decision-makers from widely applying this method in municipal water supply. First, nanofiltration requires pretreatment that uses antiscalants and cleaning solutions as well as large, conventional clarification facilities. Concentrates of reverse osmosis andnnanofiltration facilities usually constitute about 20$30 \%$ of initial feed water flow, and their discharge creates serious ecological problems. Antiscalants, which are contained in the concentrate, also create an ecological problem of phosphate pollution. It is obvious that both problems of pretreatment arrangement and concentrate disposal are attributed to fouling and scaling control and should be solved together. This article offers a new approach to solving these problems, based on the understanding of fouling mechanisms in membrane channels and the introduction of new "open channel" membrane modules with decreased fouling potential as a tool to simplify pretreatment and increase recoveries. 
Two main economic factors that influence successful RO industrial application are: operational costs to ensure pretreatment and the handling of concentrate disposal. Both of these problems and their solutions are closely connected: the necessity of adequate pretreatment is attributed to the fouling and scaling hazard as suspended particles, organics, and sparingly soluble salts can form sediments on membrane surfaces and decrease membrane product flow and rejection values. To increase recoveries, a number of techniques are being developed such as withdrawal of calcium sulphate from concentrate by precipitation on the seeds in reactor [3], lime softening to withdraw carbonate [4], to apply air stripping to increase $\mathrm{pH}$ values [5]. A Zero Liquid Discharge tools are being implemented by increasing recoveries [3-5] and reduction of concentrate volume followed by evaporation [3]. Control of scale formation in membrane channels can also be implemented by means of "seed" precipitation described in [6]. In these experiments tubular membrane modules were used. The "open" membrane channel of tubular modules provided safe operation of the pilot unit without the fear of seed particle "trapping" by a spacer mesh and fouling, that exists when spiral wound membranes are used. Also recovery can be increased using a "contact stabilization" process [7] where RO concentrate passes through a "contact" mass filter bed and calcium carbonate is precipitated on the "contact mass".

For all these cases the processes require additional energy to provide enough driving force - i.e. supersaturation value - to increase crystal growth. In these cases precipitation reactors receive $\mathrm{RO}$ concentrate after one pass through the membrane module that does not provide enough driving force for crystallization to withdraw all calcium. On the other hand, high values of concentrate flow are mainly attributed to the "fear" of exceeding the solubility limits of main sparingly soluble constituents such as calcium sulphate and calcium carbonate in $\mathrm{RO}$ concentrate, as it is recognized as subversive to membrane performance. As it was shown in a number of previous publications, fouling and scaling in commercial $\mathrm{RO}$ modules are attributed to the module design and channel geometries [8,9].

The main disadvantages of spiral wound modules are attributed to the presence of separation spacer mesh in the feed channel as it traps fouling particles and increases cross-flow channel resistance. The places (spots) where the mesh connects to the membrane surface provide "dead areas" without cross- flow that result in high concentration increase at the membrane surface, initiating the formation of crystals. Organic and colloidal matter coagulates and sediments within "dead areas", promoting expansion of the foulant layer around the "dead area". The accumulation of foulant around mesh bundles increases flow resistance - an increase that follows the filtration theory mechanism.

Figure 1a shows results of author's observations during his research devoted to understanding scaling and fouling mechanisms [8,9]. The boundary layer where the concentration polarization effect occurs can be considered a "chemical reactor", where flocculation of the suspended, colloidal and organic matter, as well as calcium carbonate crystal nucleation processes take place (Figure 1). This idea to use membrane concentration process as a driving force to remove turbidity, color and hardness seems very attractive, as no reagent is required. Foulants that sediment on the membrane surface are easily removed using hydraulic flushes.

Application of spiral wound membranes substantially reduces operating costs due to lower required cross-flow values as compared to the use of tubular configuration. This technique uses "open channel" spiral wound membranes where turbulation mesh and its influence on flow resistance is eliminated and hydraulic conditions are similar to those of the tubular configuration. The open channel configuration is described in [8]. Technical considerations to improve membrane channel geometry and avoid formation of "dead areas" are shown on Figure 1b. Modernization of the channel is developed by the author and patented.

\section{DEVELOPED TECHNIQUES USING OPEN CHANNEL MODULES}

Application of the developed "open channel" membrane modules in RO facilities that treat surface water and well water can exclude pretreatment. This, in turn, can significantly reduce start-up and operational costs of building pretreatment [8]. Elimination of the spacer mesh from the feed channel in spiral wound modules eliminates "dead" regions that provide scaling and fouling conditions. This novel concept of spiral wound module with an "open channel" configuration offers a new way to prevent scaling and fouling, and develop a new to treat water with high fouling potential. The risk of sparingly soluble salts precipitation (calcium carbonate, etc.) is minimized by the strong stability of calcium carbonate solutions. Introduction of the "open 

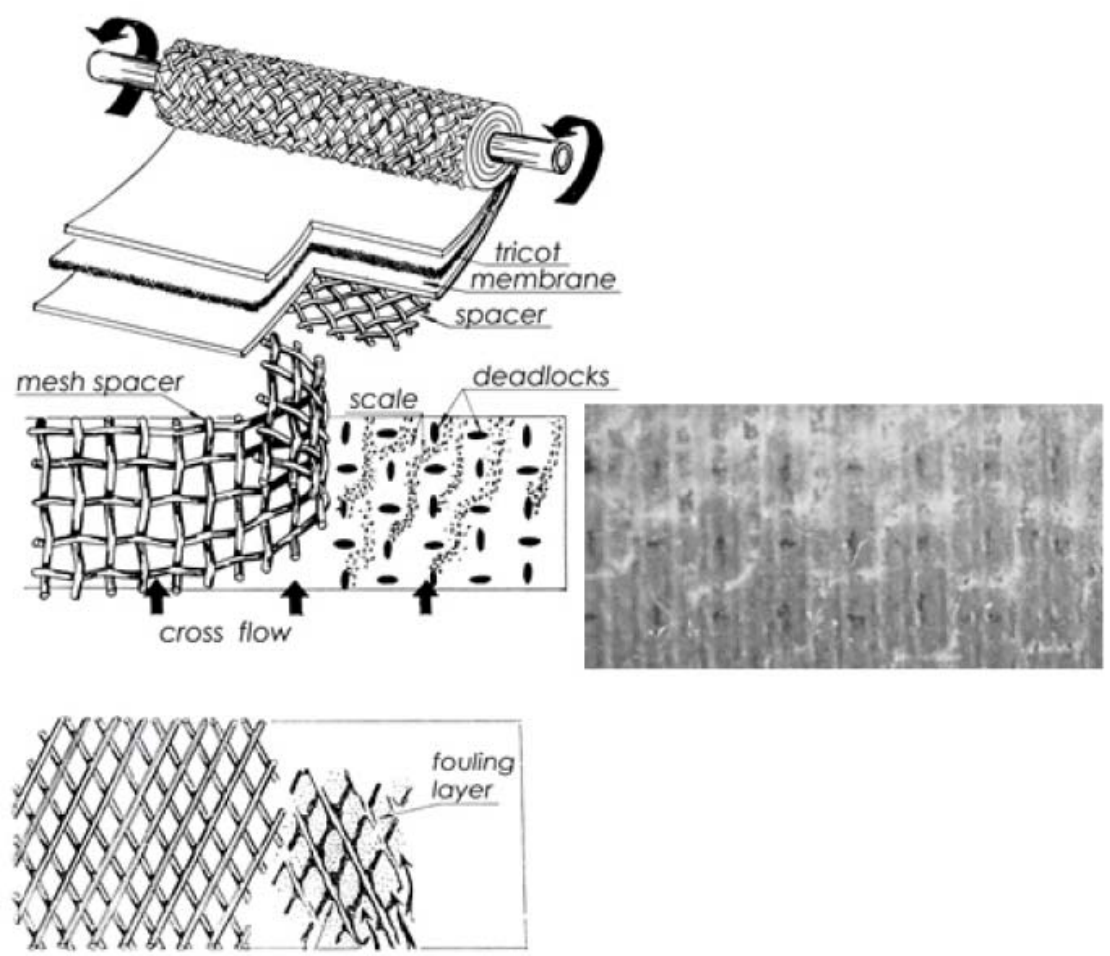

a

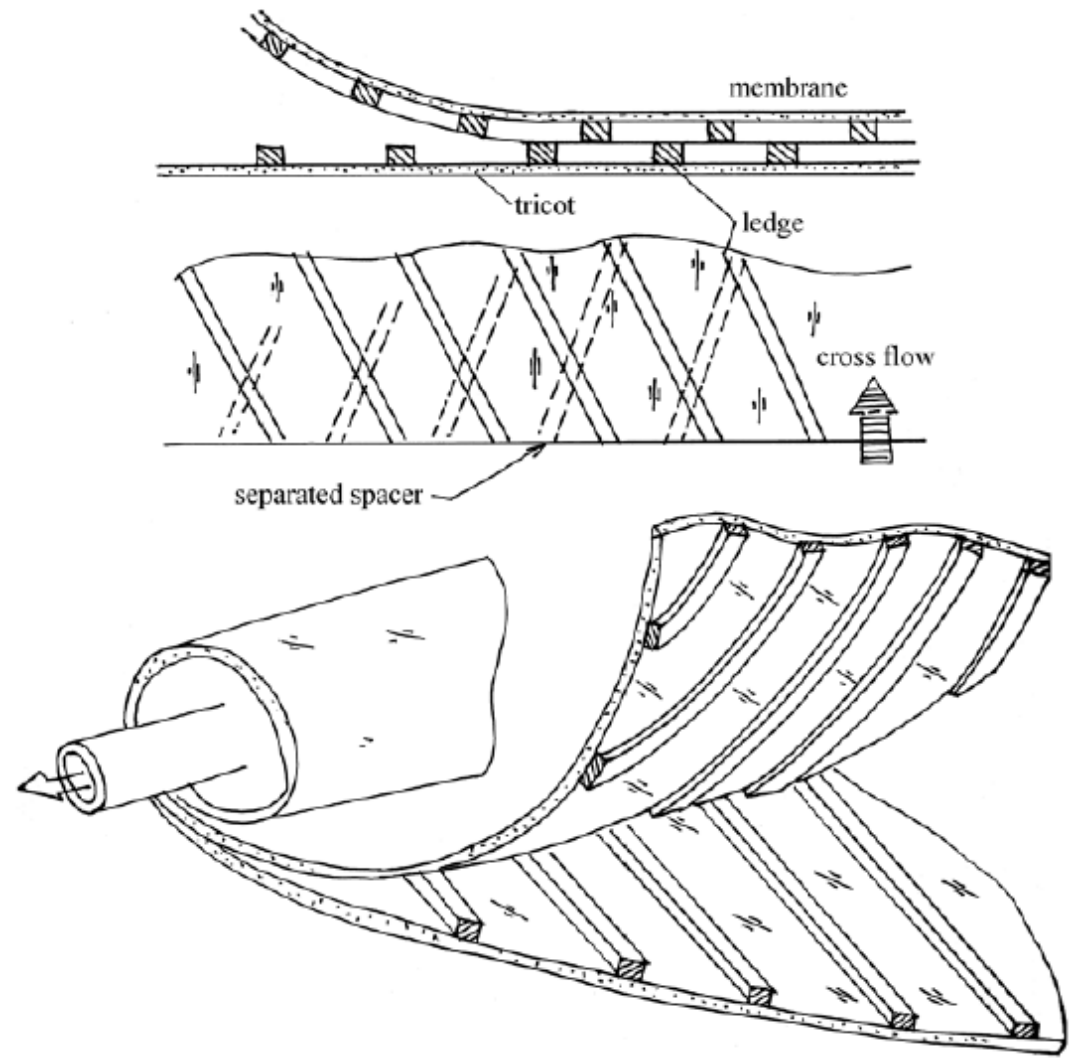

b

Figure 1: Formation of "dead" areas on membrane surface in spiral wound membrane modules (a) and their elimination in an "open-channel" configuration (b).

channel" configuration also helps to exclude measures that control scaling - such as antiscalant dosing, softening, acid addition and timely cleanings. As it was already mentioned [8], fouling control is achieved by 


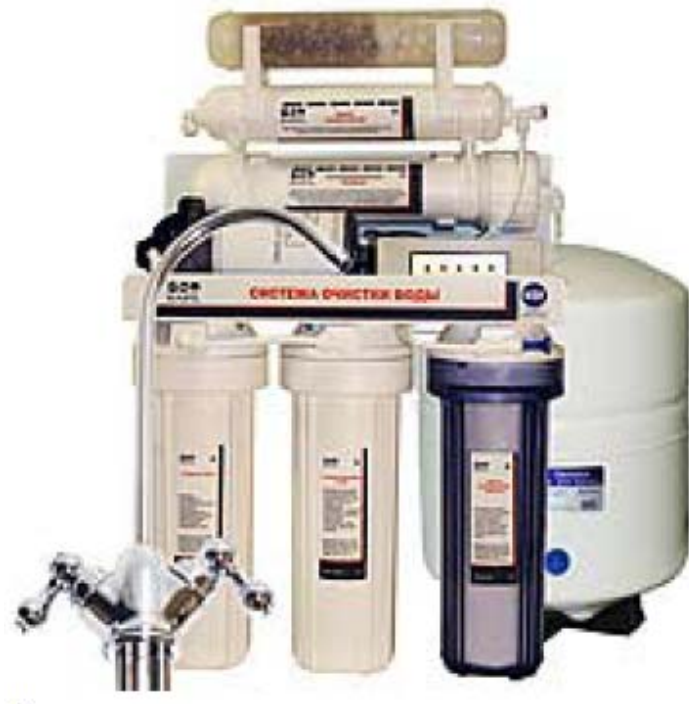

a.

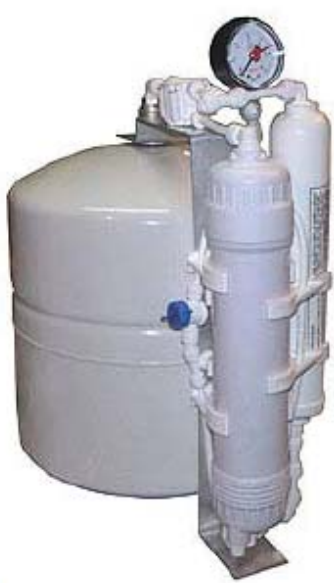

b.

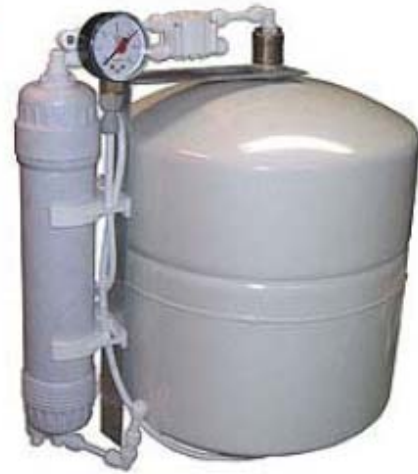

c.

Figure 2: Under-counter RO system: the use of "open channel" modules simplify pretreatment and reduce footprint.

providing sufficient cross flow velocities, flushes and cleanings.

Figure 2 shows a typical under-counter RO unit used for drinking water production (a) and a newly developed under-counter RO unit tailored with "open channel" modules (b, $c)$. Conventionally used RO systems feature at least three cartridges used not for water treatment, but for pretreatment to protect membrane from suspended matter, colloidal particles (sediment cartridges), bacteria, organics, chlorine (activated carbon sorption cartridges) and calcium carbonate (solid state antiscalant cartridges) contained in tap water that enters the membrane unit. Only membrane and post treatment cartridge (for taste and odor improvement) are used for production of quality drinking water. This large amount of pretreatment cartridges requires timely replacement and is responsible for $70-80 \%$ of operational costs needed for under-counter RO unit maintenance. The use of the "open channel" module (Figure $\mathbf{2 b}$, c) does not require these additional cartridges, and therefore, additional replacement costs. The membrane unit is thereby simpler and less expensive than the conventional prototype.

Figure 3 shows a new membrane unit developed by the author to produce quality drinking water from well water to remove hardness, iron, fluoride, ammonia, strontium, etc. The flow diagram is simple: the unit consists of pump, membrane 8040 module ("open channel" spiral wound) and pressure tank. No chemicals (like antiscalant) and no pretreatment is used.
Figure 4 shows RO units for distilled and deionized water production used in chemical and biochemical industries. These units use double stage RO principles and "open channel" RO modules in the first stage. This ensures strong reliability of the units that often are operated in auto mode and lack qualified operational staff to maintain pretreatment, add chemicals, replace cartridges and perform frequent cleanings.

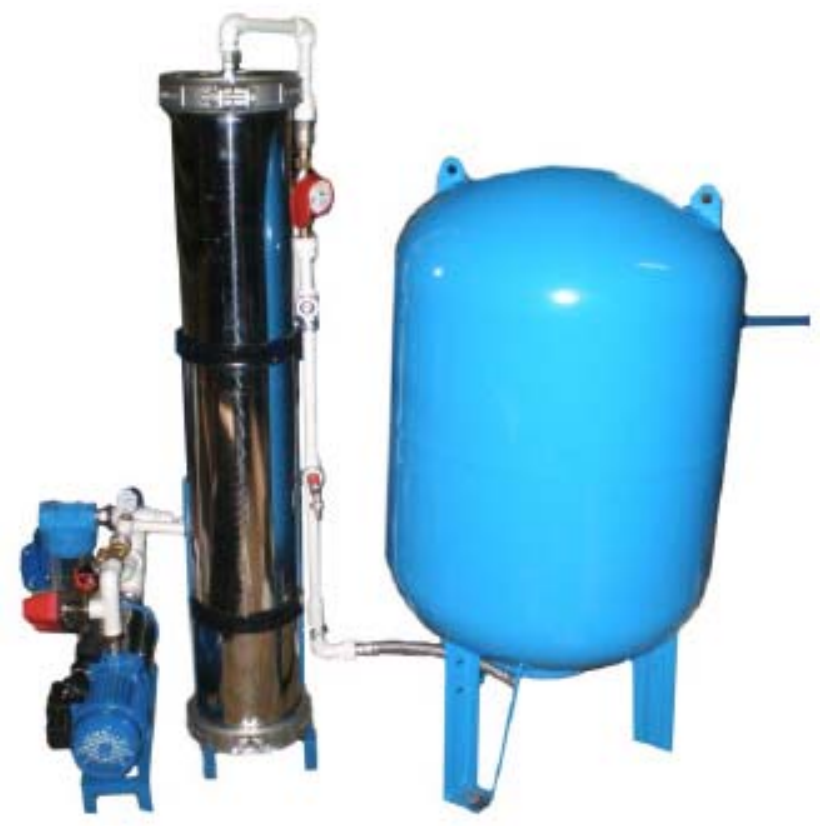

Figure 3: Membrane unit supplies 2-3 cubic meter per day of quality drinking water for home use.

As it was discussed above, elimination of the spacer mesh from the feed channels of spiral wound modules eliminates "dead" regions that provide scaling and fouling conditions while also reducing the risk of 
a.

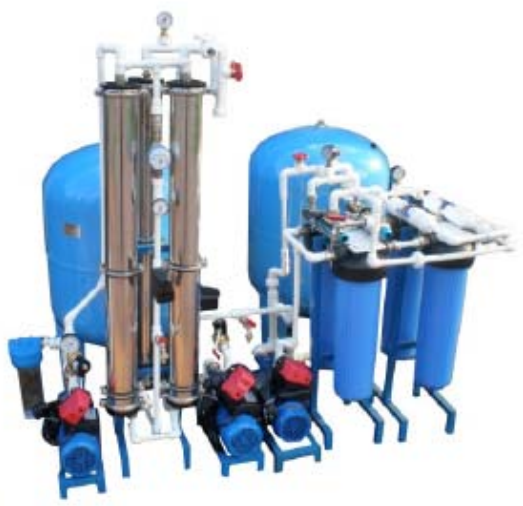

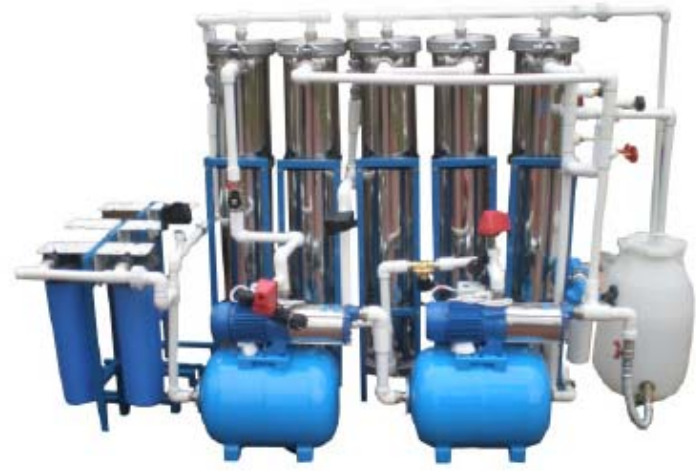

b.

Figure 4: Double stage RO units for distilled and deionized water production, production of 150 (a) and 1200 (b) liters per hour.

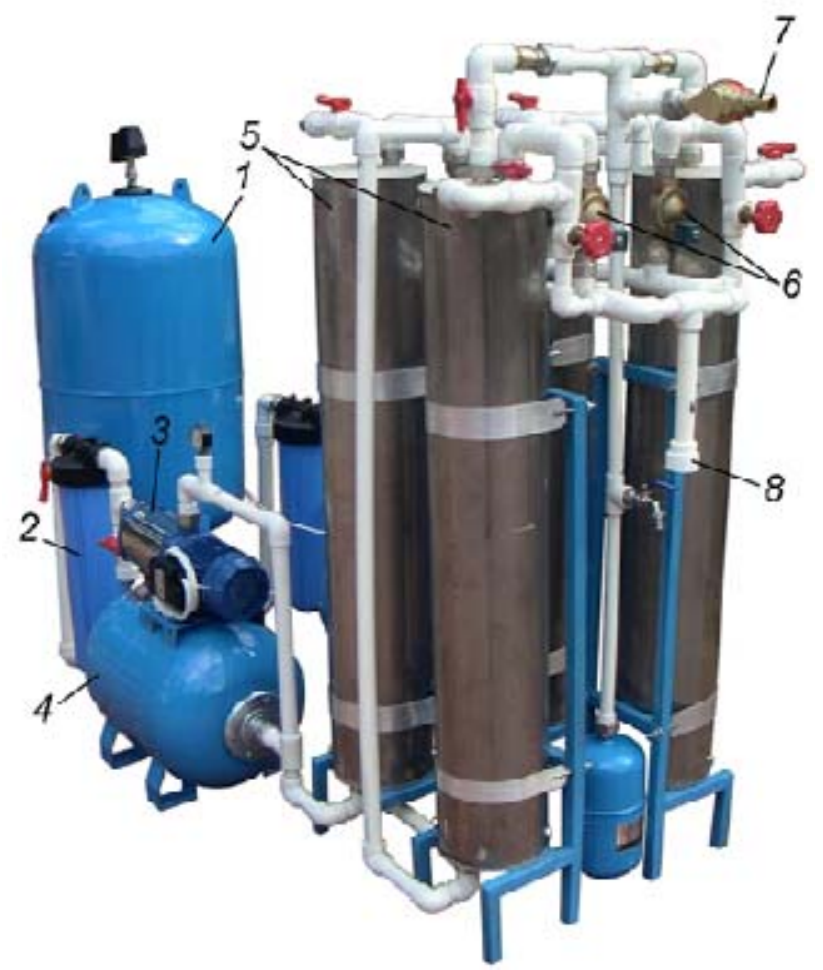

Figure 5: Nanofiltration unit for surface water treatment.

1 - pressure feed water tank; 2 - prefilter 50-100 micron; 3 feed water pump; 4 - flush water tank; 5 - nanofiltration modules; 6 - solenoid valves; 7 - clean water outlet; 8 concentrate and flush water discharge.

particle trapping and associated dramatic increase of cross flow resistance. To control colloidal fouling, automatic flushes are applied by opening of solenoid valves located on the concentrate line at the outlet of the module. Hydraulic flushes destroy fouling layers and withdraw foulants from membrane surface due to cross-flow velocity increase and water hammer initiation through rapid pressure drop. Flush modes (time intervals between flushes and flush durations) are very important to maintaining fouling control and flow velocities on the desired level.
Figure $\mathbf{5}$ shows construction of membrane unit for surface water treatment featuring "open channel" modules and built-in flushing system. Feed water is pressurized by a centrifugal pump and is forwarded to membrane module and small pressurized accumulation tank. When the solenoid flush valve is open, flow pressure drops and cross-flow velocity increases. To ensure high cross flow velocity value, pressurized feedwater tank is used.

Typical industrial scale NF and RO units to treat surface water and to produce $10-50$ cubic meters of drinking water per day are shown on Figure 6 . The units include membrane modules, pumps, built-in flush systems, product water tanks and re-pressurization pump systems tailored with ultraviolet sterilizers. The units are designed to fit into standard 20 foot containers.

Figure 7 shows the flow diagram of $\mathrm{RO}$ process to treat surface water to remove turbidity and color. The membrane unit is operated in circulation mode and recovery could reach $90-95 \%$ value. Water after flushes is collected in a special sedimentation tank. After suspended matter contained in the flush water is sedimented, water is blended with the feedwater. The sedimented sludge is further dewatered. Thus, the sedimented sludge contains all main impurities that should have been removed from the feed water, such as suspended and colloidal particles, fulvic and humic compounds that form water color that adsorb at coagulated particle surfaces.

Figure 8 shows a flow diagram of the process described above where concentrate flow is treated by a nanofiltration membrane before it is blended with the product water. This treatment aims to reject excessive TOC, suspended solids, color, hardness and bacteria from the concentrate. We use low rejection 


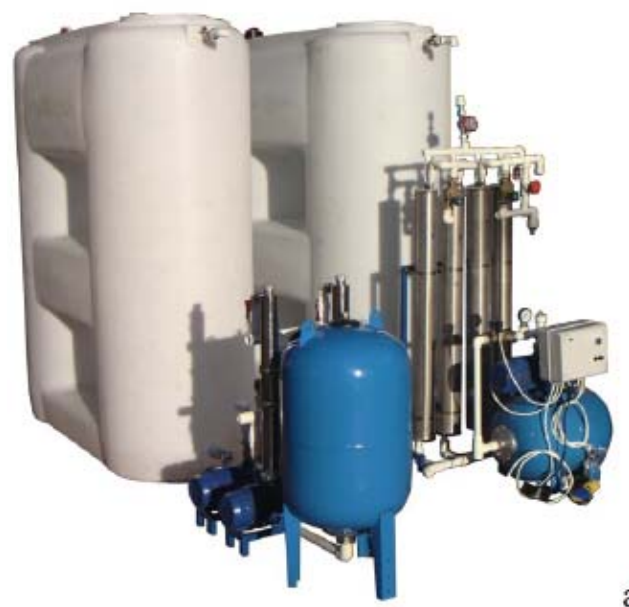

a)

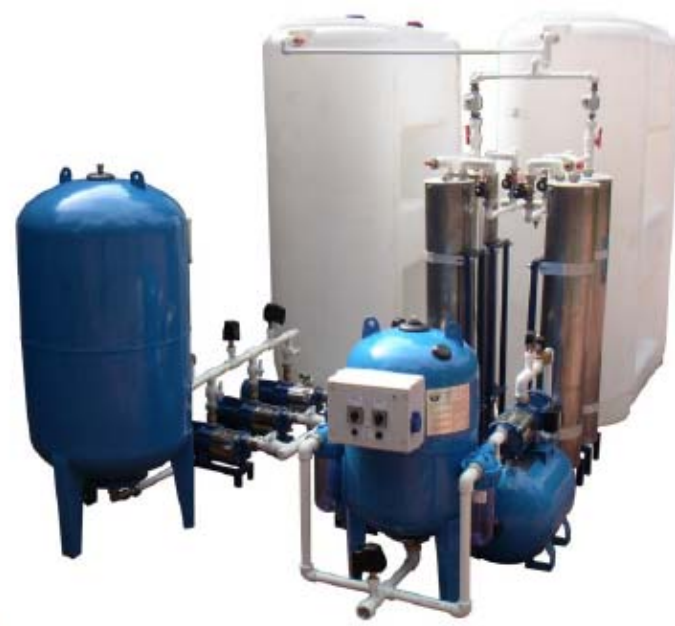

b)

Figure 6: Nanofiltration units for surface water treatment: production of $10-15$ cubic meter per day of quality drinking water; production of 50 cubic meter per day.

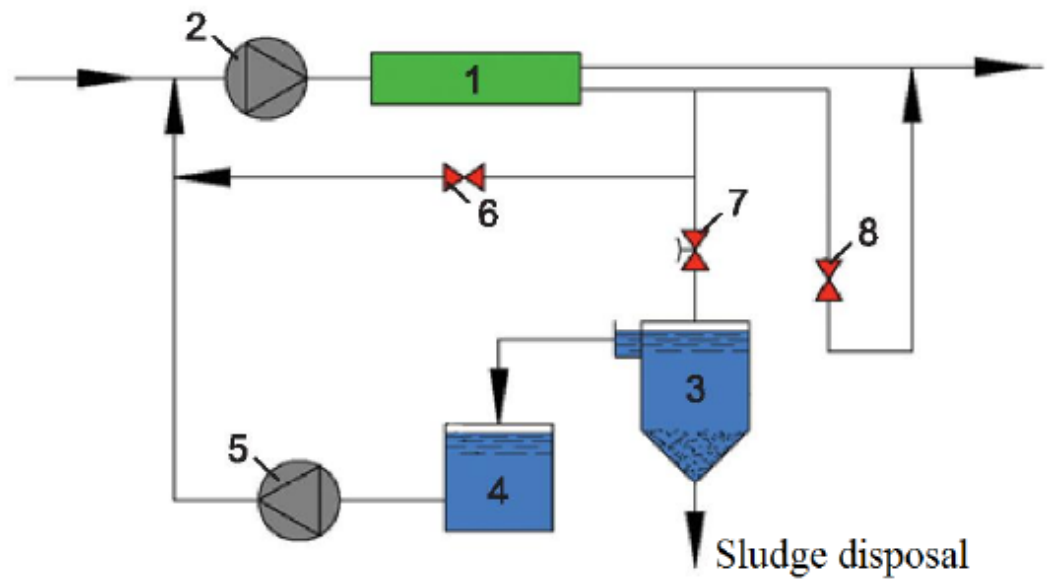

Figure 7: Flow diagram of $\mathrm{RO}$ process to treat surface water for removal of turbidity and color.

1 - open channel module; 2 - recirculation pump; 3 - flush water tank; 4 - water for reuse; 5 - water reuse pump; 6 - circulation valve; 7 -solenoid valve; 8 - pressure gauge.

nanofiltration membranes that poorly reject monovalent ions (by $40-50 \%$ ) that provide NF product water TDS only $23-30 \%$ lower than the feed water TDS. The determined values of main water ingredients and ionic species in the feed water, product water and concentrate flows are presented in Table 1.

The values of oxidity, TOC, turbidity, color, suspended solids concentration are determined experimentally during pilot testing [8]. Figure 9 shows the calculated balance of flows and TDS values of concentrate and product water. Balance calculations accounted for the amount of salts that entered the test unit and was withdrawn from it with the product flow (both first stage product flow and second stage NF product flow) and with dewatered sludge as sludge turbidity. It was also accounted that NF product water does not withdraw all salts contained in RO first stage concentrate. To reach salt "equillibrium", the second stage NF unit is designed to provide higher product flow than first RO stage concentrate flow. The NF membrane second stage unit is operated periodically using first stage RO concenrate as feed water collected in flushing tank (8). Its operation is controlled by the float switch concentrate. The amount of salts containing RO first stage concentrate that enters flush tank (8) thus equals to the amount of salts in second stage NF product water and sludge.

The described approach can be applied only for the cases when feed water contains only impurities that could be easily removed by sedimentation, such as: colloidal and suspended matter, colloidal iron, color, etc. When excessive hardness, fluoride, ammonia, pesticides etc. is contained, other techniques are utilized: only a part of concentrate is blended with 


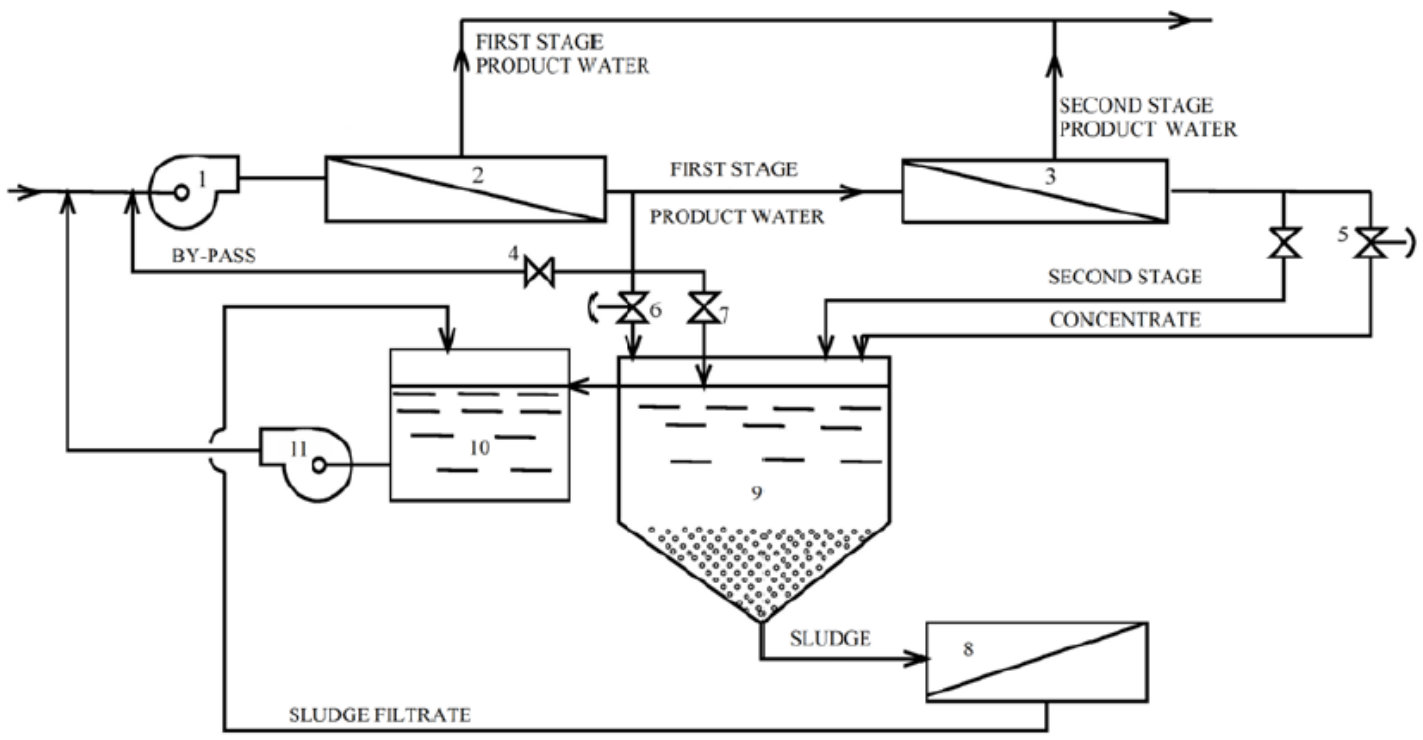

Figure 8: Flow diagram of RO process with concentrate treated by nanofiltration.

1 - pump; 2 - RO membrane module; 3 - nanofiltration second stage membrane; 4 - bypass valve; 5,6 - solenoid valves for flushing; 7 - pressure gauges; 8 - sludge dewatering system; 9 - flush water sedimentation tank; 10 - water reuse tank; 11 water reuse pump.

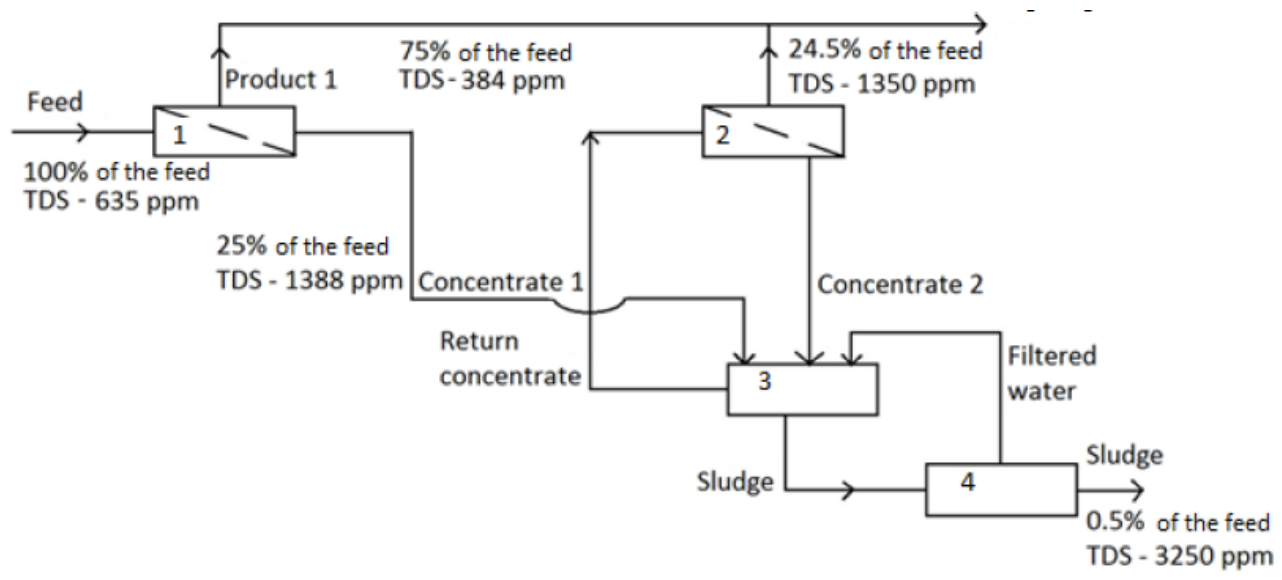

Figure 9: Flow diagram with calculated values of flows and TDS. 1 - first stage RO module; 2 - second stage nanofiltration module; 3 - flush water sedimentation tank; 4 - sludge dewatering system.

product flow that provides optimal concentrations of rejected impurities. The remaining part of the concentrate flow could be further concentrated and withdrawn with the wet sludge as sludge moisture. The amount of water in the wet sludge constitutes about $0.8-1 \%$ of the feed water amount.

As an example of an $\mathrm{RO}$ unit with decreased concentrate discharge, a membrane system with product water capacity of $15 \mathrm{cu}$. $\mathrm{m}$ per hour to remove fluoride and strontium from the well water is shown in Figures 10, 11 and 12. A low concentrate flow value is reached through the use of membrane modules on the second stage to further decrease concentrate flow. The process flow diagram is shown in Figure $\mathbf{1 0}$. Figure $\mathbf{7 b}$ shows a membrane unit (one line) that produces 5 cubic meters per hour of product water. The $20 \mathrm{c} \mathrm{m}$ per hour unit consists of four 5 cubic meter lines connected in parallel. Feedwater is pumped into nanofiltration modules (in the first stage) where it is separated into product flow (15 cubic meters per hour) and first stage concentrate flow ( 5 cubic meters per hour). First stage product flow is forwarded to the product water tank and first stage concentrate enters the second stage nanofiltration modules where it is further concentrated and separated into second stage product water (4 cubic meter per hour) and second stage concentrate (1 cubic meter per hour). The second stage product is added to the feedwater and concentrate is discharged into the sewer. Table 1 shows feedwater, product water and concentrate chemical compositions. A mass 
Table 1: Chemical Compositions of Feed Water, Product Water, and Concentrate

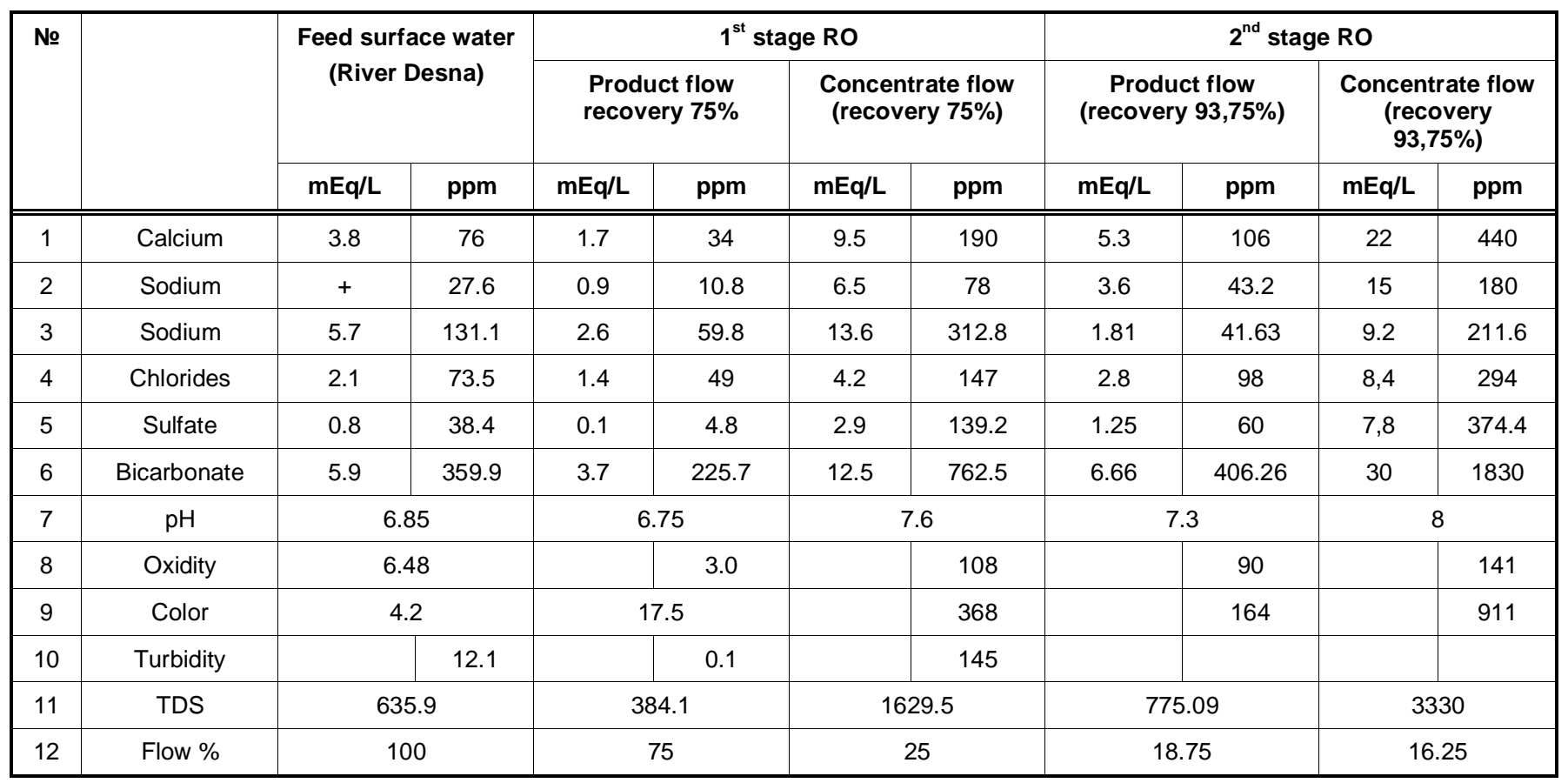

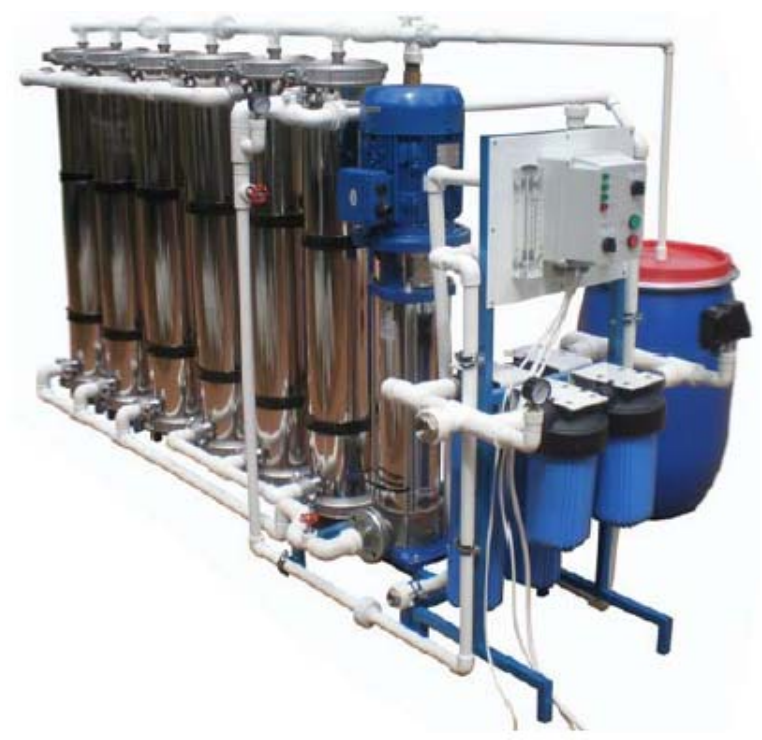

a

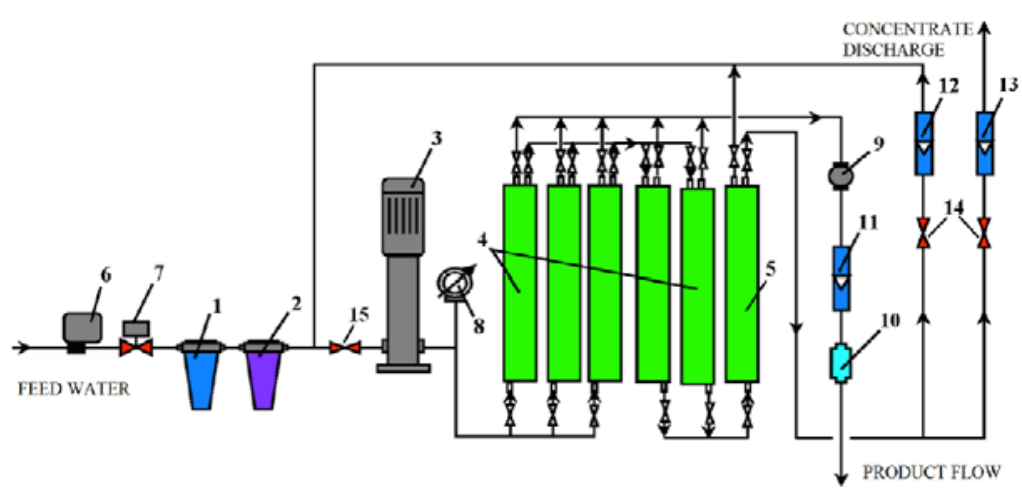

b

Figure 10: Membrane system with a reduced concentrate disposal: $\mathbf{a}$ - photograph of one block, 5 cubic $\mathrm{m}$ per hour; $\mathbf{b}-\mathrm{flow}$ diagram; 1 - 100 micron prefilter; 2 - solid state antiscalant cartridge; 3- centrifugal pump; 4 - membrane module; 5 -second stage membrane module for concentrate flow reduction; 6- pressure relay; 7 - solenoid valve; 8 - manometer; 9- product water counter; 10 - conductivity meter sensor; 11- concentrate flow meter; 12 - bypass flow meter; 13 -concentrate flowmeter; 14 pressure gauges.

balance flow diagram of the described process is presented in Figure 11. Figure 12a shows a water treatment station that includes a well water intake pavilion, a membrane unit located in a container, and the product water tank. The interior of the container is shown in Figure $\mathbf{9 b}$.
Calcium carbonate scaling hazard is recognized as a main factor that disturbs multiplied concentration of the feed water in membrane modules. The use of "open-channel" modules enables us to concentrate solutions that are supersaturated by calcium carbonate and calcium sulphate, and to develop a reagent-free technique to remove calcium carbonate water. 


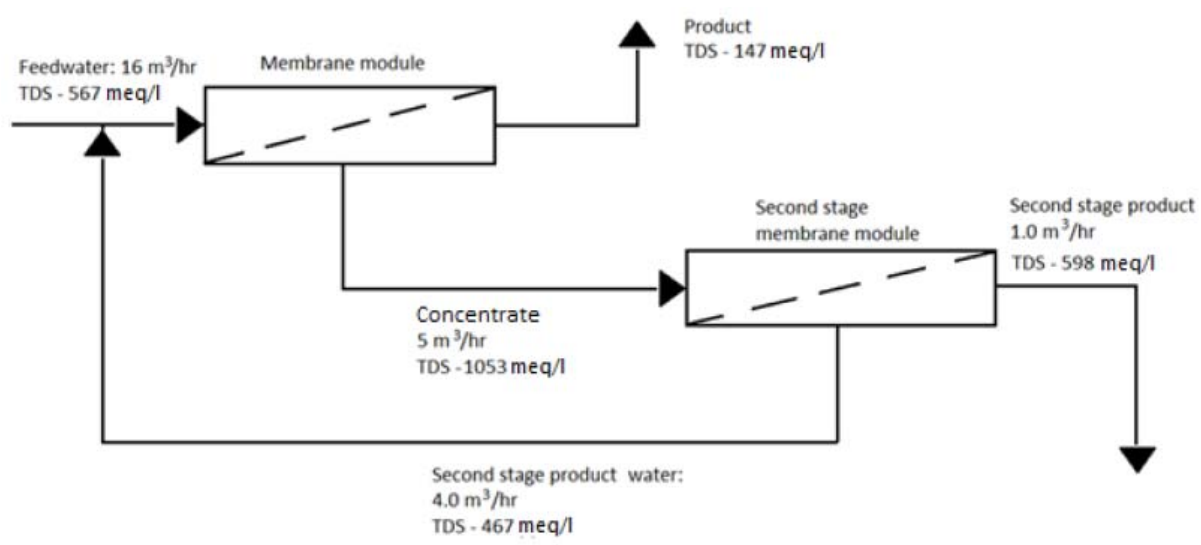

Figure 11: Flow diagram of membrane unit producing $15 \mathrm{cu} . \mathrm{m}$ per hour, showing flow and TDS values.

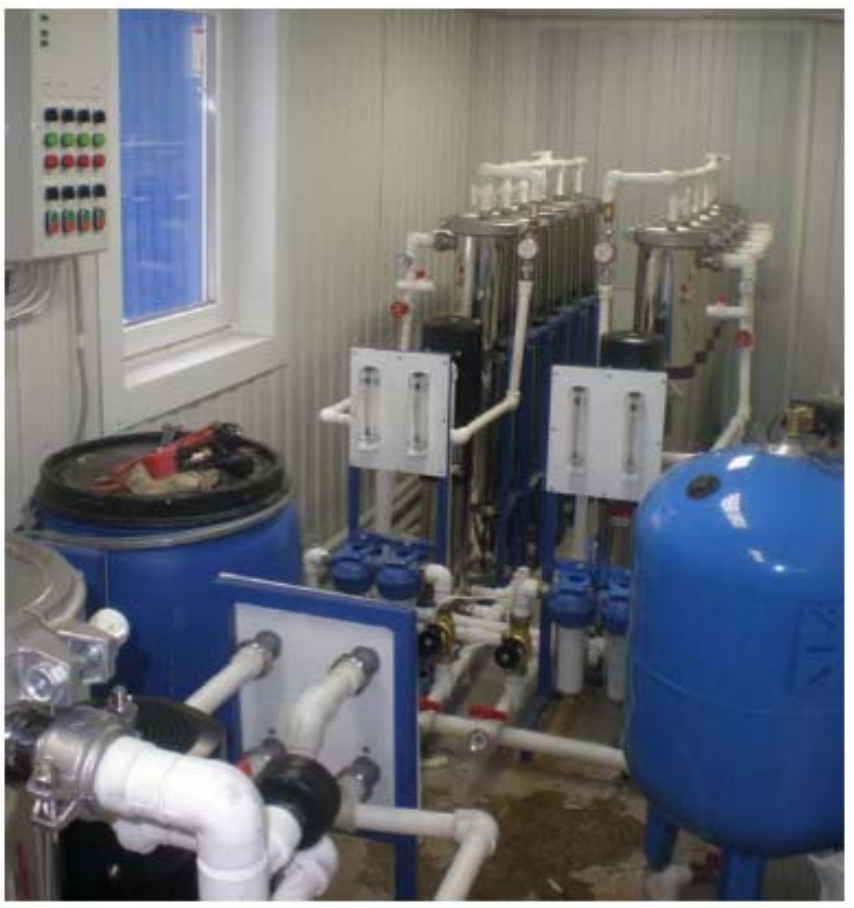

a

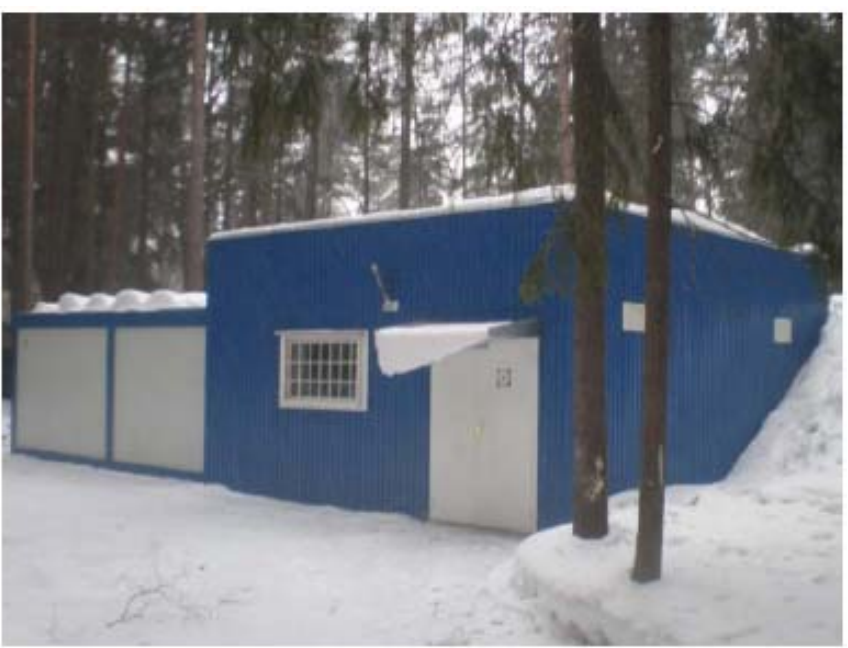

b

Figure 12: Water treatment station mounted inside the container: $\mathbf{a}$ - interior of the container; $\mathbf{b}$ - outside view of container attached to water intake.

The present report aims to investigate the possibilities of decreasing concentrate discharge (to increase recovery) and reducing pretreatment expenses mainly connected with the use of chemicals and facilities to initiate flocculation and to predict calcium precipitation. To increase recovery values, a new process is developed that uses continuous crystallization of calcium carbonate at a constant supersaturation level provided by a constant raise of concentrate TDS while $\mathrm{RO}$ is operated in circulation mode.

It is obvious that the RO process provides enough energy and "sufficient" driving force to form and grow crystals. The investigations of scaling mechanisms on membrane surfaces enables us to simulate it, implement it "outside" the membrane module, and withdraw calcium and bicarbonate ions from the concentrate stream.

The described process can be implemented only on the condition that sparingly soluble salts are not precipitated on membrane surface in the module during its operation. To provide high supersaturation values in circulation solution, the investigation uses newly developed RO spiral wound modules that have an "open channel" without the conventional spacer mesh. This spiral wound module eliminates "dead areas" that 
provide nucleation and scaling conditions while also reducing the risk of particle "trapping" and associated dramatic cross-flow resistance [7]. Membrane modules maintain high cross-flow velocities that provide a "shear-off" effect for suspended particles. Colloidal matter that adheres to membrane surfaces can be withdrawn from the module by flushing the membrane, therefore eliminating the need to remove colloidal matter from the feedwater to control fouling.

In majority cases, when drinking water is produced by $\mathrm{RO}$ unit, only partial removal of hardness, fluoride, ammonia, strontium is required. Thus, the largest part of concentrate flow can be blended with the product flow. The described approach enables us to utilize the concentrate by separating the feed water into product water flow and sedimented sludge flow (Figures 7-9).

The principles of $\mathrm{RO}$ concentrating of solutions containing sparingly soluble salts and recovery increase are described in $[8,9]$ in respect to calcium sulphate. The supersaturated solution (concentrate) after RO unit enters sedimentation tank where excessive calcium carbonate is precipitated and sedimented. Concentrate after calcium sulphate separation is forwarded back to RO unit where it is further concentrated. Thus concentrate amount can be substantially diminished. Calcium carbonate system has a different nature and cannot be withdrawn the same way $[11,12]$. To initiate calcium carbonate precipitation, a constant "driving force" should be applied to maintain constant supersaturation level. This was implemented by caustic addition in [12] and by airstrippimg [5] that increased $\mathrm{pH}$ in $\mathrm{RO}$ concentrate.

\section{WAYS TO DECREASE CONCENTRATE FLOW AND PREVENT CALCIUM CARBONATE SCALING. EXPERIMENTAL METHODS TO STUDY CALCIUM CARBONATE PRECIPITATION}

The present work aims to develop a new approach to concentrate utilization: seed mass is added to RO concentrate and excessive calcium carbonate is precipitated on the seed mass, then softened concentrate is blended with $\mathrm{RO}$ product water. Thus, softened water is produced that can be used either for drinking or technical purposes (such as boiler feed or cooling water). The described water softening method does not require chemicals (such as lime and soda), does not produce brines like sodium-cationite regeneration solution or RO concentrate to be discharged.

The main challenge to initiate calcium carbonate precipitation on the seed crystals is to create a "driving force" for crystal growth - to maintain high supersaturation levels. Calcium carbonate supersaturation depends on calcium and carbonate ion concentration values. Carbonate concentration depends on $\mathrm{pH}$ values. As was shown previously in $[11,12]$, the addition of seed crystals to calcium carbonate supersaturated solution does not initiate crystal growth as the reduction of carbonate ions decrease the $\mathrm{pH}$ value and thus decrease the supersaturation level.

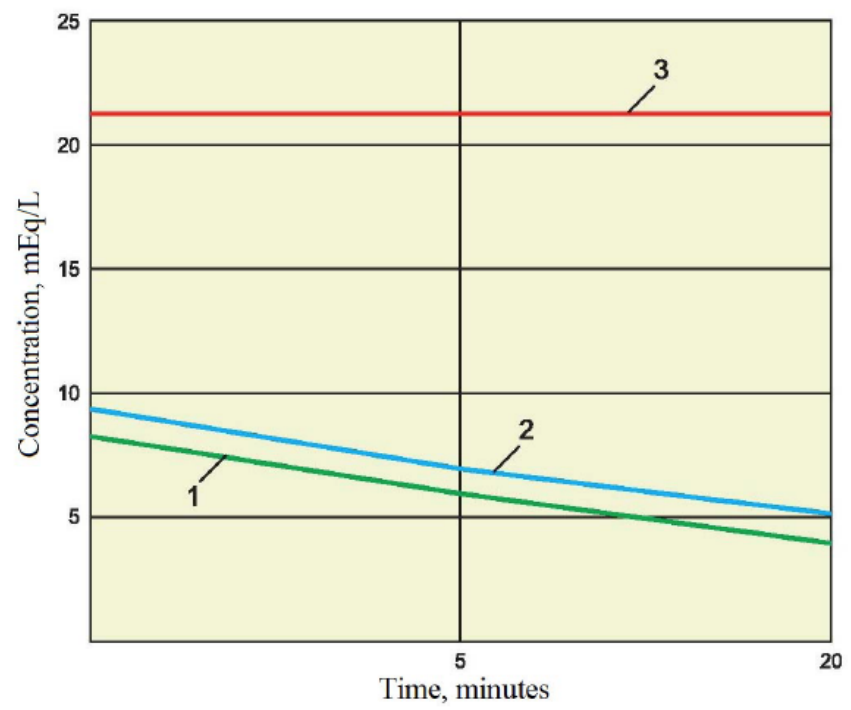

Figure 13: Calcium concentration versus time.

1 - calcium concentration; 2 - alkalinity; 3 - chloride concentration.

Figure 13 shows a decrease of calcium ion concentration values when seed crystals are added to concentrate of the $\mathrm{RO}$ unit. Precipitation rate rapidly decreases together with the Langelier Index value. Concentration values of calcium and bicarbonate ions are shown in Table 1. In [12], when calcium carbonate precipitation was investigated, caustic solution was constantly added to the calcium carbonate solution to provide constant supersaturation level.

During RO system operation, calcium and bicarbonate concentration values in $\mathrm{RO}$ concentrate constantly increase, providing a driving force for calcium carbonate crystal growth. The present article shows the experimental results of precipitation kinetics study that are influenced by various factors (such as seed concentration, supersaturation, crystal age, etc.).

A flow diagram of the experimental procedure is presented, showing the circulation loop and precipitation reactor where crystals are suspended in the flow (Figure 14a). Spiral wound modules of 1812 standard (12" length and 1,8" in diameter) tailored with 
Table 2: Concentrate Composition Transformation after Contact with Seed Mass

\begin{tabular}{|c|c|c|c|}
\hline Parameters & Feedwater & Concentrate & Concentrate after contact with seed mass \\
\hline \hline Calcium, $\mathrm{mEq} / \mathrm{l}$ & 3.75 & 8.2 & 7.4 \\
\hline Alkalinity (hydrocarbonates), $\mathrm{mEq} / \mathrm{l}$ & 3.4 & 8.4 & 4.8 \\
\hline Chlorides, $\mathrm{mg} / \mathrm{l}$ & 9.23 & 17.8 & 17.8 \\
\hline $\mathrm{pH}$ & 6.8 & 7.11 & 7.0 \\
\hline
\end{tabular}

low pressure $\mathrm{RO}$ membranes (BLN-type) manufactured by CSM ( Korea) were used in experimental studies for comparison with newly developed modules. New "open"channel" spiral wound modules were manufactured using the same flat sheet membranes, having the same dimensions and fitting the same size pressure vessel. Modules were manufactured in accordance with configuration shown on Figure $\mathbf{5}$ using rolling machine "Model № RS 4040A" supplied by "Hydrocomponents and Technologies", CA.

Natural water (surface and groundwater) was used as test solutions in experiments. To increase fouling and scaling potential of the test solution (to increase hardness, colour or turbidity), natural water was preconcentrated using $\mathrm{RO}$ modules.

To initiate calcium carbonate scaling, a test procedure should provide supersaturation conditions as a driving force for crystallization [8,9,11,12]. In described experiments high scaling potential (supersaturation) was constantly arranged due to operation of the test unit in concentration mode where product water was withdrawn.

The feedwater is constantly concentrated as the product is constantly withdrawn. "Seed" crystals are produced by addition of caustic solution to RO concentrate. In our experiments feed water (well water) was preconcentated 6 times by volume and stoichiometric amount of $1 \mathrm{~N}$ caustic solution was added to concentrate to form calcium carbonate.

Thus, calcium carbonate is constantly withdrawn from the circulating solution as supersaturation constantly provides a driving force for crystal growth. Small crystals sediment on membrane surface during membrane operation and are easily flushed from the membrane surface by applying "flushings". As seed crystals are very small they are constantly taken out of reactor by the flow. Another experimental series used a bad filter instead of reactor that trapped crystal particles (Figure 14b).
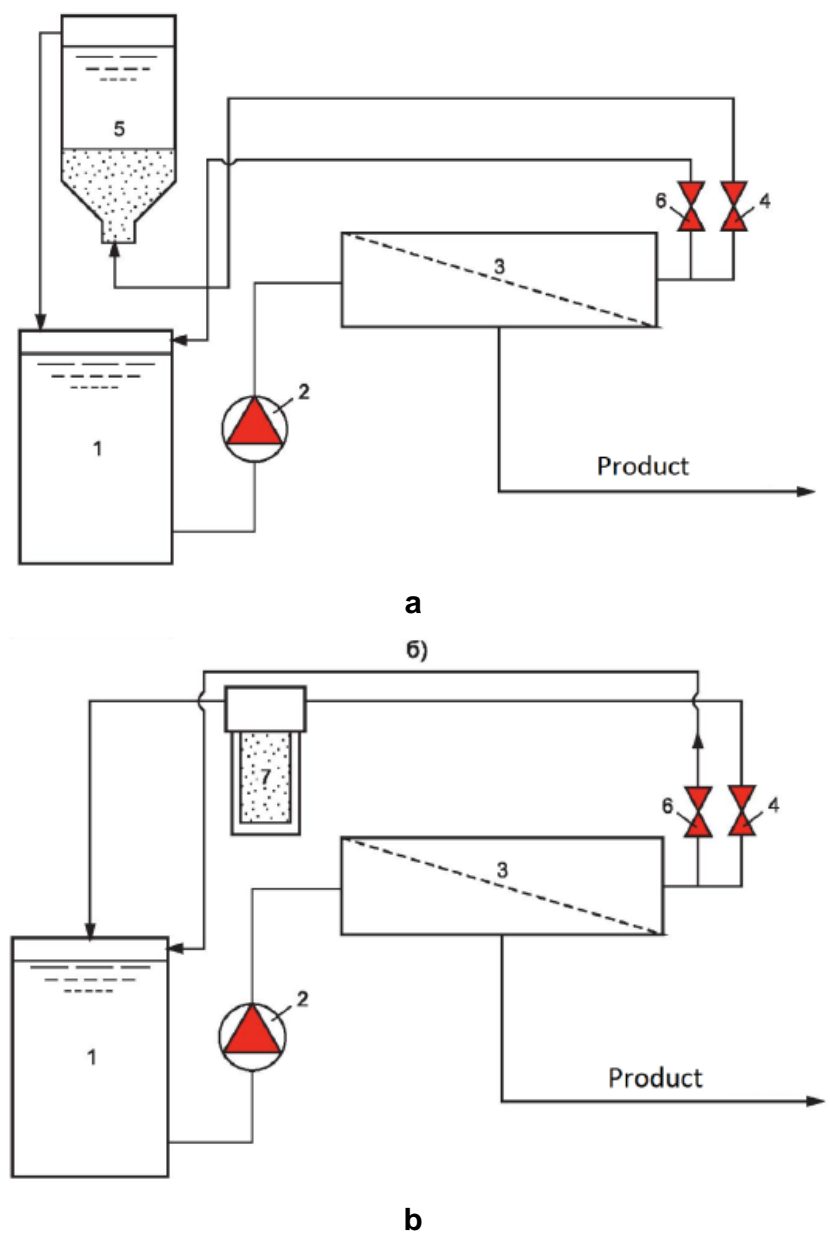

Figure 14: A flow diagram of experimental process using seed crystal reactor. (a) and bag filter to trap seed crystals (b).

\section{DISCUSSION OF RESULTS}

Figure 15 shows dependencies of calcium and bicarbonate ion concentrations in the circulating feedwater solution on the concentration ratio (feedwater volume to concentrate volume), during a test run. The increase of the seed mass increases the precipitation rate. The obtained results indicate that even small amounts of seed crystals added to the feed water provide an efficient softening of the feedwater, and withdraws the calcium carbonate mass, that by 1520 times exceeds the mass of "seed" crystals. After 
contact with the "seed" mass, concentrate can be blended with product water to produce softened water with a decreased TDS value (by the value of withdrawn calcium carbonate). Table 3 shows the concentration of ionic species in the feed water, concentrate, product water and blended solution.

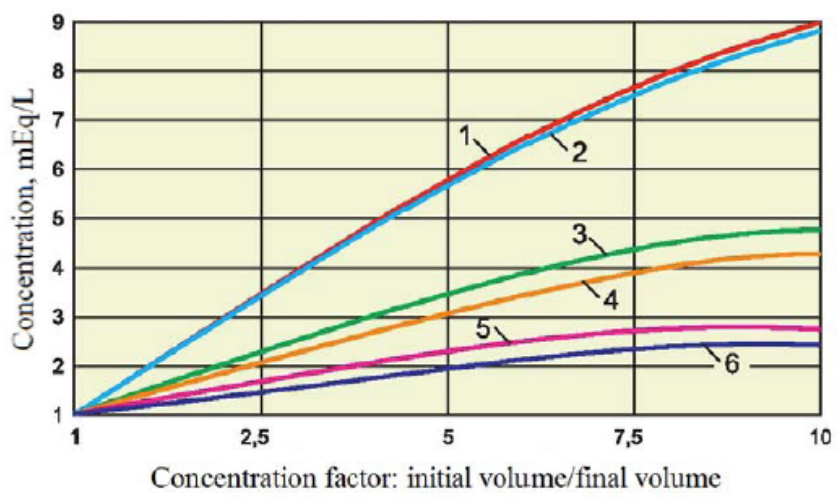

Figure 15: Various ions concentration ratio versus concentration factor values during concentrate contact with seed mass. 1,2 - chloride; 3,4 - alkalinity; 5,6-calcium.

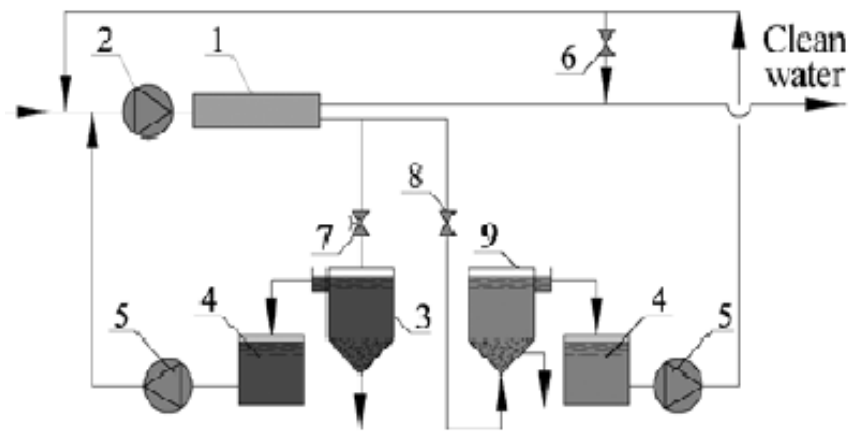

Figure 16: A flow diagram of natural water treatment with reverse osmosis membranes without concentrate discharge: 1 - membrane module, 2 - high pressure pump; 3 - flush water sedimentation tank; 4 - clean water collection tank; 5 pump; 6 - pressure valve; 7 - solenoid valve; 8 - pressure regulation gauge; 9 - calcium carbonate precipitation reactor.
Thus, the use of described techniques enables us to produce softened water without the use of reagents (as during lime and soda softening), high TDS brines (as during ion exchange softening), or RO concentrate flows (Figure 16).

Precipitated calcium carbonate (in suspended state) and carbonate particles, inside the reactor, are withdrawn from the reactor throughout the experimental run. It seemed reasonable to use a microfilter that traps particles instead of a reactor (Figure 14b). The precipitated and sedimented calcium carbonate is filled into the filter housing with a 5 -micron filter. After the RO module concentrate is forwarded to the inlet of the filter housing. During the experiment, feed water is constantly concentrated and pumped through the crystal mass and filter cartridge. The crystal mass is constantly increased as calcium carbonate is precipitated on the seed crystal surfaces due to the constant supersaturation increase.

Through the use of the described "seed mass precipitation" techniques, softened water is obtained. The described approach does not require chemicals for calcium carbonate precipitation (as in case of lime and soda softening) or ion exchange bed regeneration (as in case of ion exchange softening).

To reach the required removal of dissolved impurities such as fluoride, ammonia, strontium, arsenic etc., part of the softened water is blended with the concentrate. The amount of blended flow is calculated using equilibrium equations. Figure 17 shows examples of mass balance developed for different cases of feedwater composition.

In power industry applications, $\mathrm{RO}$ techniques are recognized as the most efficient at producing deionized

Table 3: Experimental Data Sheet

\begin{tabular}{|c|c|c|c|c|c|}
\hline Parameters & Feedwater & $\begin{array}{c}\text { Concentrate, } \\
\text { Recovery value 90\% }\end{array}$ & $\begin{array}{c}\text { Concentrate after contact } \\
\text { with seed crystals } \\
\text { Recovery value 90\% }\end{array}$ & $\begin{array}{c}\text { Product } \\
\text { water }\end{array}$ & $\begin{array}{c}\text { Mixture (concentrate } \\
\text { and product) }\end{array}$ \\
\hline \hline Calcium, mg/l & 4.6 & 38.6 & 10.4 & 0.32 & 1.3 \\
\hline Hardness, meq/l & 6.7 & 57.8 & 33.4 & 0.71 & 4.1 \\
\hline Alkalinity, meq/l & 6.1 & 47.6 & 28.1 & 1.4 & 4.1 \\
\hline Chlorides, mg/l & 37.9 & 331 & 326 & 16.4 & 49.1 \\
\hline $\mathrm{pH}$ & 6.8 & 8.0 & 7.9 & 6.1 & 6.7 \\
\hline
\end{tabular}




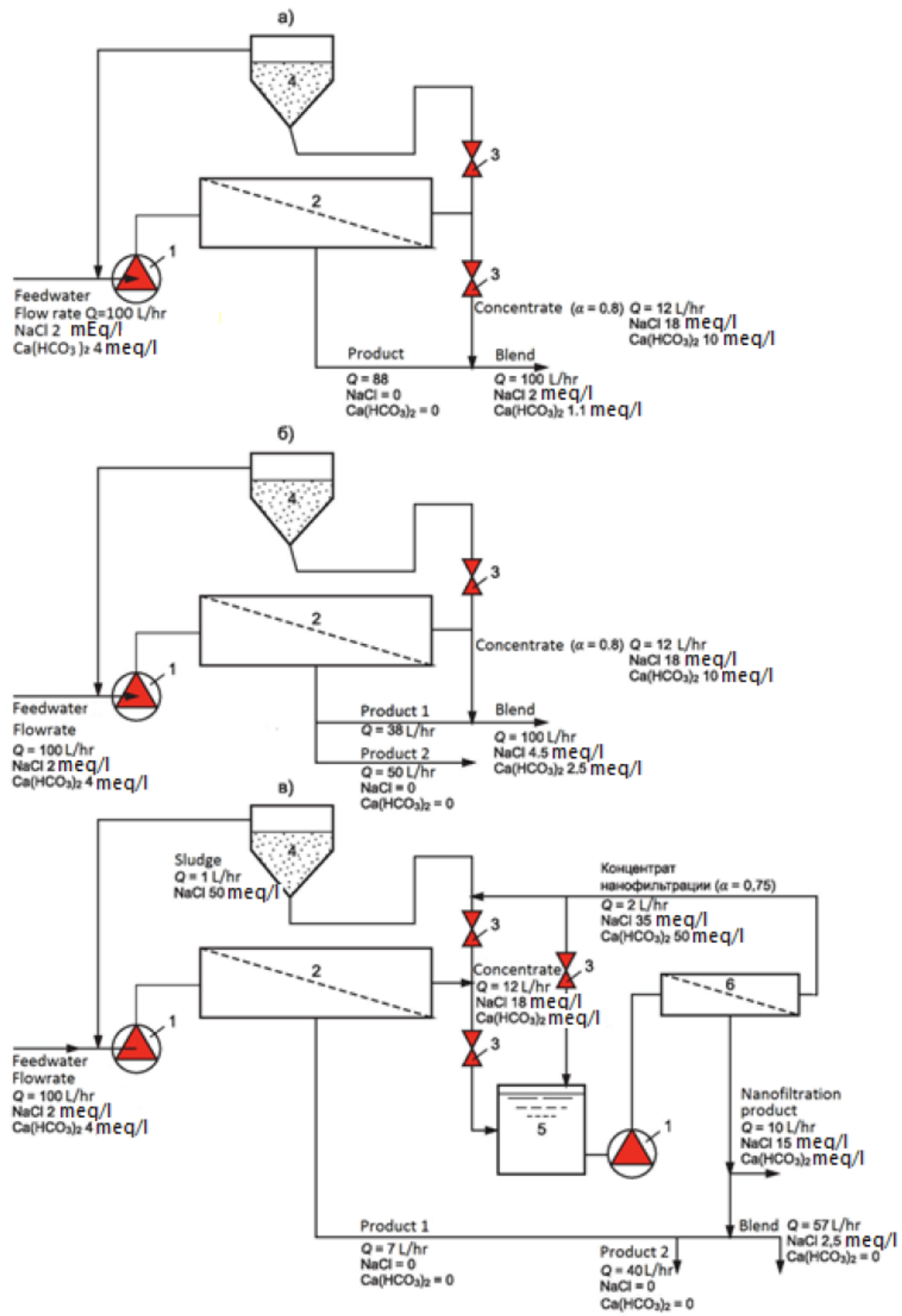

Figure 17: Examples of mass balance calculations for different cases of product water composition.

and softened water. But detailed technological surveys reveal that high operational costs for $\mathrm{RO}$ maintenance are attributed mostly to chemical cleaning and the pretreatment to prevent scaling and fouling. Pretreatment costs also increase due to concentrate flow that constitutes about $25-30 \%$ of RO product flow. In power industries, concentrate is often utilized by adding to cooling water flow or boiler feed water for heating. The use of $\mathrm{RO}$ does not solve the main ecological problems connected with chemical consumption and wastewater (after softening and clarification processes discharge). The developed techniques enable us to remove calcium carbonate from RO concentrate and to utilize it as a softened water added to cooling water or water for heating purposes.

Part of the deionized water product can be used for boiler feed purposes and another part can be mixed with concentrate (after treatment) to form softened 
water. As is shown in Table 2, concentrate loses carbonate hardness (determined as $\mathrm{CaCO} 3$ ) after seed crystal treatment, and its TDS is reduced by the amount of withdrawn calcium carbonate. Thus, the described approach enables us to produce deionized water, softened water (with TDS value close to that of the initial feed water), and sludge.

The developed process is very attractive for implementation by power industries for deionized water production. Figure 18 shows a new process flow diagram that produces water for power industries for two purposes: deionized water for steam production and softened water for cooling and heating. Deionized water is produced by double stage RO and is further post treated using mixed bed filters. The first stage of this double stage $\mathrm{RO}$ contains membrane modules "with open channels" that directly treat surface water. Mixed bed filter is used after second stage RO, product water TDS is about $1 \mathrm{ppm}$. Mixed bed filters are regenerated very rarely and regeneration solution can be added to the first stage concentrate, this does not significantly increase its TDS value (an increase of 5$10 \mathrm{ppm}$ ). After the first RO stage, concentrate is further softened in reactor, treated by NF unit and mixed with a part of first stage product water to produce water for cooling and heating purposes.
The developed techniques provide a chemical-free method without waste water discharge (identified as "liquid discharge"). According to this technique, a part of the product water is blended with the "softened" concentrate after its contact with the "seed" mass. Thus, feedwater is divided into 2 streams: deionized product water (used for steam production) and softened water with a TDS value that does not exceed the feedwater TDS (used for heating or cooling). Low hardness values ( 0.005 milliequivalent per liter) or low TDS values could be achieved by implementation of double stage RO.

Suspended and colloidal foulant contained in the feed water can be flushed out of the membrane module, sedimented, and dewatered. Growing seed mass can be withdrawn separately from the system and sedimented.

The described approach to utilize RO concentrate by calcium carbonate precipitation and withdrawing is distinguished by the use of $\mathrm{RO}$ process as a driving force to provide supersaturation and crystallization. Caustic solution is used not to maintain supersaturation values, as during conventional reagent softening, but to produce seed crystals (initiate homogenous crystallization). The required caustic amount is by 30 -

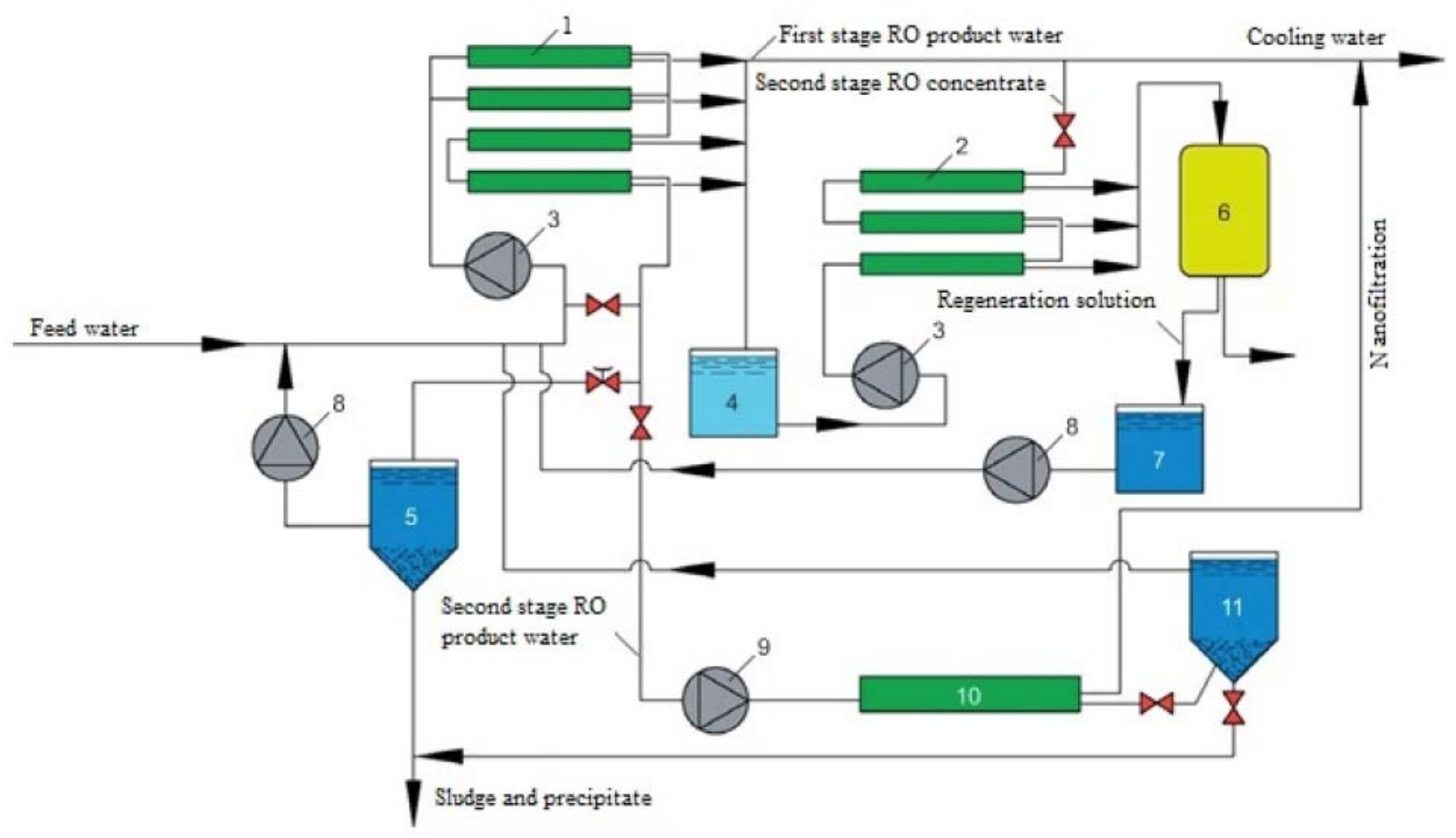

Figure 18: Flow diagram for boiler feed water and heating water production.

1 - "open channel" membrane modules; 2 - second stage membrane modules; 3 - high pressure pumps; 4 - first stage product water accumulation tank; 5 - flush water tank; 6 - mixed bed filter; 7 - regeneration solution tank; 8 - pumps; 9 - nanofiltarion unit pump; 10 - nanofiltration modules; 11 - calcium carbonate precipitation reactor. 
50 times lower than stoichmetric value required for conventional calcium carbonate precipitation.

\section{CONCLUSIONS}

Results of conducted studies could be used to introduce new water treatment techniques to directly treat natural water with high fouling and scaling potential using proposed "open-channel" spiral wound modules tailored by nanofiltration and reverse osmosis membranes.Elimination of the "dead areas" responsible for scale formation provides a new solution to increase recovery and utilize concentrate.

A new technique is described that enables us to increase recoveries and utilize $\mathrm{RO}$ concentrate that consists of calcium carbonate precipitation on the "seed" crystal mass, withdrawal of excessive calcium carbonate and further blending of softened concentrate with RO product water. As a result, softened water is obtained with lower TDS and hardness than of the initial feed water.

The developed techniques do not require chemicals and do not discharge concentrated brines.

\section{REFERENCES}

[1] Laine J-M, Vial D, Moulart P. Statusafter 10 years of operation - overview of UF technology. Proceedings of the Conference on Membranes in Drinking and Industrial Water Production, Paris, France, 3-6 October, 2000; pp.17-27.

[2] Ventresque C, Gisclon V, Bablon G, Shagneau G. (France). An outstanding feat of modern technology: the Mery-sur-Oise Nanofiltration treatment Plant (340,000 cu. metr per day). Proceedings of the Conference on Membranes in Drinking and Industrial Water Production, Paris, France, 3-6 October, 2000; pp. 1-16.

[3] Cohen Y. Interstage chemical demineralization for high recovery $\mathrm{RO}$ demineralization. The 3-rd Sede Boqer Conference on Water Technologies 2012 "Advanced Technologies in Water Management", October 15-17, 2012; Book of Abstracts, p. 55.

[4] Gilron J. Flow reversal as a tool in use of crystallizer/ secondary $\mathrm{RO}$ treatment for high recovery desalination. Ibid, p. 56.

[5] Segev R, Hasson D, Semiat R. Improved high recovery brackish water desalination process based on fluidized bed air stripping. Desalination 2011; 281: 75-79. http://dx.doi.org/10.1016/j.desal.2011.07.043

[6] Harries RC. A field trial of seeded reverse osmosis for the desalination of a scaling -type mine water. Desalination 1985; 56: 227-236.

\section{http://dx.doi.org/10.1016/0011-9164(85)85027-X}

[7] Veespareni S, Bond R. Getting this last drop: new technology for treatment of concentrate. Tianjin IDA World Congress 2013 on Desalination and Water Reuse, October 20-25, China 2013; TIAN 13-357.

[8] Pervov AG. Scale formation prognosis and cleaning procedure schedules in reverse osmosis operation. Desalination 1991; 83: 77-118. http://dx.doi.org/10.1016/0011-9164(91)85087-B

[9] Pervov AG, Andrianov AP. Application of membranes to treat wastewater for its recycling and reuse: new considerations to reduce fouling and increase recovery up to 99 per cent. Desalination and Water Treatment 2011; 35: 2-9.

[10] Niewersch C, Zayat-Vogel B, Melin T, Wessling M. Nanofiltration for sulphate elimination in groundwater affected by open coal mining. The conference book of the 6th IWA Specialist. Conference on Membrane Technology for Water and Wastewater Treatment, Aachen, Germany 4-7 October, 2011; pp. 151-157.

[11] Okazaki M, Kimura S. Scale Formation on Reverse Osmosis Membranes. Desalination 1977; № 21.

[12] Reitz L. Development of a broad-spectrum antiscalant for reverse osmosis system."12-th Annu. Conf. Water Supply Improv. Assoc., Orlando, Fla, Tech Proc May 13-18, 1984; vol. 1: Sess. 1-6". Topsfield, Mass. s.a., F 1-26.

(C) 2014 Alexei Pervov; Licensee Lifescience Global.

This is an open access article licensed under the terms of the Creative Commons Attribution Non-Commercial License (http://creativecommons.org/licenses/by-nc/3.0/) which permits unrestricted, non-commercial use, distribution and reproduction in any medium, provided the work is properly cited. 